МахмУтова Е. Н., ЧУГАНСКАЯ А. А., ВоеводА Е. В.

СПЕЦИФИКА ФАКТОРНОЙ СТРУКТУРЫ МЕЖКУЛЬТУРНОЙ КОМПЕТЕНТНОСТИ СТУДЕНТОВ...

РосСиЙский психологичЕский жУРнАл, 2020, Т. 17, № 3, 60-75. doi: 10.21702/rpj.2020.3.5

СОЦИАЛЬНАЯ ПСИХОЛОГИЯ

УДК 159.99:316.42 doi: $10.21702 /$ rpj.2020.3.5

Оригинальная научная статья

\title{
Специфика факторной структуры межкультурной компетентности студентов международного профиля в гендерном аспекте
}

\author{
Елена Н. Махмутова', Анфиса А. Чуганская ${ }^{2 *}$, Елена В. Воевода ${ }^{1}$ \\ ${ }_{1}^{1}$ МГИМО МИД России, г. Москва, Российская Федерация \\ 2 Институт системного анализа ФИЦ ИУ РАН, г. Москва, Российская Федерация \\ *E-mail: anfisa.makh@gmail.com \\ ORCID ID: http://orcid.org/0000-0002-2341-1131, http://orcid.org/0000-0001-9727-6406, \\ http://orcid.org/0000-0002-5141-8074
}

\begin{abstract}
Аннотация
Введение. Статья посвящена оценке межкультурной компетентности студентов-межАународников. Цель нашего исслеАования - определение особенностей межкультурной компетентности в группе российских женщин и мужчин, получающих высшее образование по специальности, связанной с межкультурным взаимодействием.

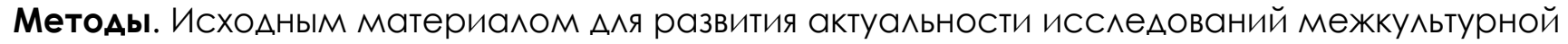
компетентности были взяты илеи Аокумента Совета Европы о к^ючевых компетенциях, лежащих в основе культуры демократии. Нами были опрошены 54 студента-межАународника в возрасте 17-23 лет по методике М. Барретта, операционализировавшего эту концептуальную модель Совета Европы. Новизна исследования - в сравнении и анализе оракторной структуры теоретической и эмпирической моделей межкультурной компетентности российских респонАентов (с учетом их генАерной принаАлежности) в отношении ценностей, поведенческих Установок, практических навыков и необходимых знаний Аля межкультурного взаимодействия. Результаты. Аля российских респонАентов была поАтвержАена гипотеза об отсутствии различий в количестве фракторов теоретической и эмпирической моделей межкультурной компетентности. В группе россиянок рейтинг фракторов межкультурной компетентности состави^: 1 - практические навыки, 2 -толерантность, 3 - сопереживание, 4 - гражАанское сознание. В группе российских мужчин рейтинг факторов межкультурной компетентности представлен: 1 - уважением и ответственностью, 2 - алаптивностью, 3 - сопереживанием, 4 -толерантностью.

ОбсужАение результатов. При сохранении четырехоракторной структуры в теоретической и эмпирической молелях межкультурной компетентности солержание фракторов по Аанным российской выборки существенно отличается от теоретической молели. В нашем исслеАовании респонденты проявили семантическое и инструментальное разнообразие в компонентах межкультурной компетентности: Аля женщин успешность межкультурного взаимодействия зависит от практических навыков, самообразования, умения слушать и понимать, готовности к сотрудничеству, толерантности; Аля мужчин - от уважения и ответственности, аАаптивности, знаний и их критического осмысления. Концептуальная модель развития межкультурной компетентности Аолжна совершенствоваться с учетом генАерной и профрессиональной специфики и иметь реализацию в образовательных программах.
\end{abstract}


МахмУтова Е. Н., ЧУГАНСКАЯ А. А., ВОЕвоДА Е. В.

СПЕЦИФИКА ФАКТОРНОЙ СТРУКТУРЫ МЕЖКУЛЬТУРНОЙ КОМПЕТЕНТНОСТИ СТУДЕНТОВ...

РосСИЙСКИЙ пСИХОЛОГИЧЕСКИЙ ЖУРнАл, 2020, Т. 17, № 3, 60-75. doi: 10.21702/rpj.2020.3.5

СОЦИАЛЬНАЯ ПСИХОЛОГИЯ

\section{КАючевые слова}

межкультурная компетентность, модель компетентности, межкультурное взаимодействие, образование, стуленты-межАународники, генлер, факторный анализ, ценности, поведенческие установки, профрессиональная Аеятельность

\section{Основные положения}

$\triangleright$ проблема развития межкультурного взаимолействия является особенно актуальной Аля стулентов, получающих образование межАунаролного профриля;

$\checkmark$ существуют различные поАхоАы к пониманию межкультурной компетентности;

$\checkmark$ в рамках более операционализированной молели межкультурной компетентности, преА^оженной М. Барреттом, вылеляются ее четыре фрактора: ценности, установки, практические навыки, знания и их критическое осмысление;

$\triangleright$ у российских стулентов-межАународников выявлена четырехфакторная молель межкультурной компетентности, оАнако их смысловое наполнение отлича^ось от модели М. Барретта; $>$ в группе Аевушек выявлены фракторы межкультурной компетентности: практические навыки, толерантность, сопереживание, гражданское сознание; в группе юношей: уважение и ответственность, алаптивность, сопереживание, толерантность.

\section{Для цитирования}

Махмутова, Е. Н., Чуганская, А. А. и Воевода, Е. В. (2020). Специфика факторной структуры межкультурной компетентности студентов международного профиля в гендерном аспекте. Российский психологический журнал, 17(3), 60-75. doi: 10.21702/rpj.2020.3.5

Дата получения рукописи: 29.04.2020

Дата окончания рецензирования: 28.05.2020

Дата принятия к публикации: 05.06.2020

\section{Введение}

В последние годы происходит трансформация теории профессионального образования, которая имеет далеко идущие последствия (Liferov \& Kostikova, 2017; Гонина, 2017). В профессиональной культуре будущего специалиста считается очень важным аспект межкультурного взаимодействия. Способность специалистов понимать людей с различными культурными традициями и самобытностью признается частью профессиональной культуры (Griffith, Wolfeld, Armon, Rios, \& Liu, 2016; Воевода, 2016). Они должны уметь лучше интерпретировать и согласовывать явления в сфере своего профессионального общения (Костикова, 2018; Чуганская, 2018).

Миграция и глобальные процессы в мире вызывают научный интерес специалистов по межкультурному взаимодействию (Berry, 1997) и множество исследований по межкультурному измерению в высшем образовании (Lantz-Deaton, 2017). Всё больше внимания уделяется академической адаптации студентов-международников к культуре и образовательной среде университета. Психологические, социальные и лингвокультурные виды адаптации студентов-международников рассматриваются с различных точек зрения (Barrett, Byram, Lázár, Mompoint-Gaillard, \& Philippou, 2014; Mahmutova, 2019).

В современном обществе можно отметить «тенденцию гендерной деполяризации», демонстрирующую изменчивость поведенческих моделей мужчин и женщин и различные 
МахмУтОва Е. Н., ЧУГАНСКАЯ А. А., ВОевОДА Е. В.

СПЕЦИФИКА ФАКТОРНОЙ СТРУКТУРЫ МЕЖКУЛЬТУРНОЙ КОМПЕТЕНТНОСТИ СТУДЕНТОВ...

РосСиЙский психологичЕский жУРнАл, 2020, Т. 17, № 3, 60-75. doi: 10.21702/rpj.2020.3.5

СОЦИАЛЬНАЯ ПСИХОЛОГИЯ

уровни реализации гендерных норм и ценностей (Айвазова, 2017; Клецина и Иоффе, 2017). Через ценности раскрывается истинный смысл гендерных ролей как в широком контексте на уровне больших социальных групп, так и в форме самореализации конкретного человека, его черт личности (Bartel-Radic \& Giannelloni, 2017). В некоторых европейских странах гуманизации и взаимообогащению общественных отношений способствует сближение стандартов поведения мужчин и женщин на уровне исполнения определенных гендерных ролей (Bowen, 2020). Профессиональная деятельность, как важная часть жизни многих современных женщин наряду с исполнением семейных ролей, значительно расширила возможности личной самореализации и, соответственно, субъективного благополучия женщин (Радина, 2012). Таким образом, в исследованиях межкультурного взаимодействия, в рамках которого формируется межкультурная компетентность, обозначено влияние глобальных социальных, профессионального, образовательного, гендерного факторов.

Теоретический и методологический анализ литературы по моделям межкультурной компетентности показал, что исследования различаются по степени универсальности рассмотрения проблем межкультурного взаимодействия. В отечественной литературе основы концепций и теорий межкультурной компетентности заложены трудами Т. Г. Стефаненко, В. С. Агеева, Н. М. Лебедевой, Л. Г. Почебут, Г. У. Солдатовой, О. Е. Хухлаева и др. Если Т. Г. Стефаненко разрабатывала основы этой теории со стороны этнокультурной идентичности и путей совершенствования межкультурных коммуникаций (Стефаненко, 2009; Stefanenko \& Kupavskaya, 2010), то в работах Л. Г. Почебут межкультурная компетентность рассматривается как часть общей коммуникативной компетентности личности с когнитивными, эмоциональными, поведенческими составляющими, выраженная в следующих компонентах: культурологические знания и умения, адекватность в кросс-культурных контактах, толерантность, ассертивность и сенситивность (Почебут, 2007, 2017).

При построении авторской комплексной модели межкультурной компетентности О. Е. Хухлаев с соавторами также отводит важную роль межкультурной коммуникации и взаимодействию (Хухлаев и Чибисова, 2010; Хухлаев и др., 2020). «Совокупность знаний, личностных особенностей, побуждений и конкретных навыков, способствующих эффективному достижению целей в межкультурном взаимодействии, получила название межкультурной компетентности» (Солдатова и Пантелеев, 2007, с. 12-13). Однако теории межкультурной компетентности рассматриваются либо как процессуальная сторона межкультурной коммуникации (Солдатова и Шайгерова, 2015), либо в их обосновании прочитывается утилитарное назначение такой теории как методической базы для конструирования различных программ межкультурных тренингов (Корнилова, 2012).

Современные диссертационные исследования межкультурной компетентности проводятся в широком спектре гуманитарных наук. Культурологи, социологи, политологи, педагоги, психологи при всем разнообразии теоретико-методологических подходов в качестве объекта исследований выделяют межкультурное взаимодействие либо в области межкультурных контактов (Садохин, 2009), либо любой профессиональной деятельности с введением понятия профессиональной межкультурной компетентности (Писаренко, 2011), либо педагогической деятельности, формирующей межкультурную компетентность как образовательный результат личностной интеграции (Янкина, 2006), либо в попытках диагностировать психологические показатели межкультурной компетентности с построением «психологических профилей межкультурной компетентности» (Гридунова, 2018). В отношении психологических составляющих 
МахмУтова Е. Н., ЧУГАНСКАЯ А. А., ВОЕвоДА Е. В.

СПЕЦИФИКА ФАКТОРНОЙ СТРУКТУРЫ МЕЖКУЛЬТУРНОЙ КОМПЕТЕНТНОСТИ СТУДЕНТОВ...

РосСИЙСКИЙ пСИХОЛОГИЧЕСКИЙ ЖУРнАл, 2020, Т. 17, № 3, 60-75. doi: 10.21702/rpj.2020.3.5

СОЦИАЛЬНАЯ ПСИХОЛОГИЯ

межкультурной компетентности во всех указанных исследованиях выделены те или иные аспекты, например, ценностные ориентации (Янкина, 2006), положительная устойчивая мотивация к межкультурному общению (Писаренко, 2011), самоконтроль, самосознание, локус контроля, эмпатия (Логашенко, 2015) и др. Современные российские психологи проявляют большой интерес к такому отношению, как терпимость к неоднозначности в контексте профессиональной культуры специалиста (Солдатова и Пантелеев, 2007). В межкультурных контекстах исследуются сложные ситуации и субъекты, которые хорошо работают в слабо прогнозируемых или экстремальных условиях, в позитивном и конструктивном ключе справляются с неопределенностью, чувствуют себя комфортно в незнакомых ситуациях (Oreshkin, Shlykov, Shevchenko, Kostikova, \& Belogurov, 2019).

Толерантность к двусмысленности обычно анализируется в двух направлениях - принятие двусмысленных условий и избегание двусмысленности с целью достижения четкости; второй аспект сосредоточен на переменной непереносимости двусмысленности (Корнилова и Чумакова, 2014). Однако и на сегодняшний момент актуальной остается мысль В. С. Агеева о дефиците психологических знаний, специальных исследований и разработок в области регуляции межэтнического взаимодействия (Агеев, 1990, с. 134) - основы формирования межкультурной компетентности. Последовательная разработка проблем межкультурной компетентности со стороны анализа процессов аккультурации и межкультурных отношений проводится Н. М. Лебедевой с соавторами (Лебедева, Лунева, Стефаненко и Мартынова, 2003; Лебедева, Татарко и Берри, 2016). Исследованию различных навыков, важных для развития межкультурной компетентности, посвящены современные работы российских авторов. Так, для принятия решений в ситуациях диалога культур отмечаются навыки аналитического и критического мышления (Kostikova, Cherniavskaya, Balakhovskaya, \& Zakharchenko, 2019); для достижения целей профессиональной деятельности в поликультурном обществе выделяются навыки сотрудничества, достижения консенсуса и поддержки оптимистичного настроя других членов группы (Stepanov, Andreev, Gavzov, Novikov, \& Kostikova, 2019).

Более детальный анализ научных работ по проблемам межкультурной компетентности показывает наличие в их теоретических подходах и исследовательских позициях следующих особенностей. Во-первых, межкультурная компетентность рассматривается в общем объектном поле межкультурного взаимодействия с обозначением культурологической, педагогической, психологической и других профессиональных предметных ориентаций. Вовторых, межкультурная компетентность представляется формой осуществления, следствием и результатом разнообразных процессов межкультурной коммуникации. В-третьих, не сформировано полномасштабное представление о психологических основаниях межкультурной компетентности. В-четвертых, в процессе научно-исследовательского поиска находится вопрос операционализации понятия межкультурной компетентности, а также ее компонентов и интегративных качеств.

Учитывая все обозначенные моменты, для разработки теоретических аспектов и расширения возможностей практического применения концепций межкультурной компетентности нами были изучены комплексные исследования британских психологов и педагогов, разрабатывающих идеи развития межкультурной компетентности в контексте гражданской идентичности и формирования гражданственности и демократической культуры (Barrett, 2018). Borghetti (2017) исследует необходимость учета этических проблем при оценке межкультурной компетентности. Byram (2008) показывает, как можно формировать межкультурную 
МахмУтОва Е. Н., ЧУГАНСКАЯ А. А., ВОевОДА Е. В.

СПЕЦИФИКА ФАКТОРНОЙ СТРУКТУРЫ МЕЖКУЛЬТУРНОЙ КОМПЕТЕНТНОСТИ СТУДЕНТОВ...

РосСиЙский психологичЕский жУРнАл, 2020, Т. 17, № 3, 60-75. doi: 10.21702/rpj.2020.3.5

СОЦИАЛЬНАЯ ПСИХОЛОГИЯ

компетентность и гражданственность посредством преподавания языков. Byram, Golubeva, Hui, \& Wagner (2016) также исследуют различные практики в образовании, которые развивают межкультурную компетентность и гражданственность. В анализируемой литературе принципы демократического общества рассматриваются в значительной степени через идеи межкультурной компетентности и гражданственности (Deardorff, 2011; Porto \& Byram, 2015). Такой подход является методологически оправданным, т. к. основан на согласованном международном документе Совета Европы «Компетенции для демократической культуры». В этом документе обоснована взаимозависимость между культурой демократии и культурным диалогом в обществе, характеризующимся социальным многообразием, где межкультурная компетентность как постоянный динамический процесс основывается на активно и гибко используемых психологических ресурсах индивидуумов с целью реагирования на новые обстоятельства и адаптации (Council of Europe, 2016). Разумеется, концепция культуры демократии, используемая в документе Совета Европы, не эквивалентна понятию и концепции межкультурной компетентности. Однако межкультурную компетентность можно рассматривать как часть комплекса основополагающих критериев демократического общества. Для российских авторов ссылка на этот документ Совета Европы стала отправной точкой разработки, например, ресурсного подхода к формированию межкультурной коммуникативной компетентности у студентов вуза (Большакова, 2019).

В нашем исследовании было важно показать в теоретическом плане связь межкультурной компетентности с другими факторами межкультурного взаимодействия, прежде всего с гендерным. При этом гендер понимается нами как социальный пол и соотносится с традиционными проявлениями мужских и женских гендерных ролей. Практическая цель нашего исследования состояла в операционализации положений документа Совета Европы и работ зарубежных исследователей применительно к российским студентам, получающим высшее образование по специальности, связанной с межкультурным взаимодействием, для более адекватной их профессиональной подготовки в вузе международного профиля.

В качестве наиболее полной и хорошо операционализированной была выбрана модель М. Барретта (оценку этой модели см., например, Barrett et al., 2014; Wagner, Perugini, \& Byram, 2017). В своей работе он дает определение межкультурной компетентности как «набора ценностей, установок, навыков, знаний и их критического осмысления, которые необходимы для понимания и уважения тех, кто воспринимается как культурно отличные от нас, для осуществления эффективного взаимодействия и коммуникации с ними, для установления позитивных и конструктивных отношений с ними» (Barrett, 2018, р. 95). Автор выделил 20 основных высказываний, которые были объединены в 4 фактора: ценности, установки, практические навыки, знания и их критическое осмысление (Barrett, 2018).

Достижению цели нашего исследования способствовало предварительное использование методики оценки межкультурной компетентности российских студентов в более ранних отечественных работах. Исследователи изучали понимание учащимися культурных ценностей в контексте их профессиональной культуры (Ilyushina, Prishvina, Shevchenko, Kostikova, \& Belogurov, 2018) и пришли к выводу о необходимости совершенствования высшего образования для содействия многогранному личностному и профессиональному развитию (Kostikova, Prishvina, llyushina, Fedotova, \& Belogurov, 2018). Ориентированное на будущую работу преподавание обеспечивает формирование как межкультурной, так и профессиональной компетентности (Kostikova, Prishvina, llyushina, Krutova, \& Fedotova, 2018). 
МахмУтова Е. Н., ЧУГАНСКАЯ А. А., ВОЕвоДА Е. В.

СПЕЦИФИКА ФАКТОРНОЙ СТРУКТУРЫ МЕЖКУЛЬТУРНОЙ КОМПЕТЕНТНОСТИ СТУДЕНТОВ..

РосСИЙСКИЙ пСИХОЛОГИЧЕСКИЙ ЖУРнАл, 2020, Т. 17, № 3, 60-75. doi: 10.21702/rpj.2020.3.5

СОЦИАЛЬНАЯ ПСИХОЛОГИЯ

Объект эмпирической части нашего исследования - межкультурная компетентность как социально-психологический феномен демократического общества.

Предмет исследования - особенности компонентов межкультурной компетентности в группе российских студентов (девушек и юношей). В качестве компонентов межкультурной компетентности рассматривались межкультурные компетенции.

Изучение особенностей межкультурных компетенций в группе российских юношей и девушек, получающих высшее образование по специальности, связанной с межкультурным взаимодействием, стало целью нашего исследования. Для реализации цели были сформулированы следующие задачи:

- разработать план исследования межкультурной компетентности для российской выборки;

- сформировать группу респондентов, отвечающих цели исследования;

- подготовить необходимые материалы для проведения опросов и бесед с респондентами;

- осуществить статистическую обработку полученных данных;

- интерпретировать полученные данные и сформулировать выводы.

В соответствии с целями и задачами исследования были выдвинуты следующие гипотезы:

Гипотеза 1: существуют различия в содержании факторов межкультурной компетентности между теоретической моделью М. Барретта и эмпирическими данными в двух группах российских студентов-международников юношей и девушек.

Гипотеза 2: существуют различия в содержании факторов межкультурной компетенции в группах российских студентов между юношами и девушками.

\section{Методы}

В основу эмпирического исследования межкультурных компетенций была положена модель М. Барретта (Barrett, 2018), разработанная по рекомендациям документа Совета Европы (Совет Европы, 2016). Такой выбор был обусловлен достаточной операционализацией модели межкультурной компетентности в предложенном М. Барретом опроснике, который содержит 20 утверждений с предложением их оценить по 10-балльной шкале. Это позволяет изучить степень выраженности у российских студентов каждого из 20 компонентов межкультурной компетентности. Респондентам была предложена русскоязычная версия опросника М. Барретта, которая ранее была использована в работах российских авторов (llyushina et al., 2018; Kostikova, Prishvina, llyushina, Fedotova, \& Belogurov, 2018; Kostikova, Prishvina, llyushina, Krutova, \& Fedotova, 2018). Инструкция была сформулирована следующим образом: «Уважаемые респонденты! Перед Вами 20 утверждений, представленных в 4 блоках, которые в той или иной степени характеризуют уровень развития Вашей межкультурной компетентности. Оцените Ваш уровень каждого из качеств по десятибалльной шкале, где 1 - наименьшее развитие и 10 -наибольшее развитие качества, и отметьте в таблице соответствующую оценку».

В исследовании приняли участие студенты 1-го курса факультета «Международные экономические отношения» Московского государственного института международных отношений (МГИМО МИД России). У этих студентов уже есть определенное понимание важности социального и межкультурного взаимодействия, которое они приобрели в рамках общего образования, но такое понимание еще не достигло уровня развития навыков межкультурного общения в форме профессиональных компетенций. Наше исследование было построено по принципу пилотажного исследования факторной структуры межкультурной компетентности в группе студентов-международников ввиду высокой значимости данных для развития 
МахмУтОва Е. Н., ЧУГАНСКАЯ А. А., ВОевОДА Е. В.

СПЕЦИФИКА ФАКТОРНОЙ СТРУКТУРЫ МЕЖКУЛЬТУРНОЙ КОМПЕТЕНТНОСТИ СТУДЕНТОВ...

РосСиЙский психологичЕский жУРнАл, 2020, Т. 17, № 3, 60-75. doi: 10.21702/rpj.2020.3.5

СОЦИАЛЬНАЯ ПСИХОЛОГИЯ

профессиональных навыков будущих специалистов в области международных отношений, в том числе с учетом гендерного аспекта. Респондентами стали 54 человека: 31 женщина (возраст от 17 до 19 лет, медиана 18 лет, средняя 18,22 года) и 23 мужчины (возраст от 17 до 23 лет, медиана 18 лет, средняя 18,52 года). Таким образом, выборка состояла из 57 \% женщин и 43 \% мужчин, что соответствует соотношению студентов по этому направлению обучения.

Статистический анализ данных был проведен с помощью программы «Statistica 6.0». Для сравнения детерминирующих параметров межкультурной компетентности в теоретической модели М. Барретта и эмпирических данных в группе российских студентов-международников использовался факторный анализ по методу максимального правдоподобия с реализацией процедуры вращения Varimax. Факторизация данных проводилась для данных в 2 группах: оценочные баллы респондентов по каждому из 20 утверждений опросника в группах девушек и юношей.

В рамках плана исследований были сформулированы два этапа:

1. Анализ компонентов межкультурной компетентности на основе модели М. Барретта в группах российских девушек и юношей.

2. Определение компонентов межкультурной компетентности путем факторизации эмпирических данных в группах российских студентов-международников с учетом гендерного аспекта.

\section{Результаты}

Результаты эмпирического эксплораторного исследования были получены в двух группах российских студентов-международников - юношей и девушек. На основе факторизации оценочных баллов по каждому из 20 утверждений (переменных) опросника М. Барретта были выявлены факторные структуры межкультурной компетентности для каждой из гендерных групп студентов-международников.

В группе девушек студенток-международников было выделено 4 фактора с общим процентом объясняемой дисперсии $68 \%$. Факторная структура межкультурной компетентности на основе полученных данных в этой группе соответствует количеству факторов в теоретической модели М. Барретта. Однако их содержательное наполнение отличается. В полученных данных в группе девушек студенток-международников были выделены следующие факторы:

фактор 1 - «практические навыки» (43\% общей объясняемой дисперсии);

фактор 2 - «толерантность» (9\% общей объясняемой дисперсии);

фактор 3 - «сопереживание» (8\% общей объясняемой дисперсии);

фактор 4 - «гражданское сознание» (6\% общей объясняемой дисперсии).

Компонентный состав каждого из факторов включал от одного до пяти переменных (утверждений опросника) со значимым показателем факторной нагрузки (табл. 1). В таблице указаны наиболее значимые переменные, составляющие не менее 70 \% вклада дисперсии в фактор.

Можно отметить, что в структуре оценки межкультурной компетентности в группе девушек студенток-международников первый фактор включал выражения 1-3 и 5-6 фактора «практические навыки» опросника Барретта. Фактор идентичен по теоретической модели Барретта и эмпирическим данным, за исключением пункта 4 опросника.

Во второй фактор вошли выражения 1-2 фактора «установки» опросника Барретта. Он отражает уважение, признание и открытость культурному разнообразию. В целом его можно обозначить таким социально-психологическим понятием, как «толерантность». Третий фактор отражает эмоциональный и оценочный компонент межкультурной компетентности - сопереживание, 
МаХМУТОва Е. Н., ЧУГАНСКАЯ А. А., ВОЕВОДА Е. В.

СПЕЦИФИКА ФАКТОРНОЙ СТРУКТУРЫ МЕЖКУЛЬТУРНОЙ КОМПЕТЕНТНОСТИ СТУДЕНТОВ...

РосСИЙСКИй пСИХологИЧЕСКИй ЖУРнАл, 2020, Т. 17, № 3, 60-75. doi: 10.21702/rpj.2020.3.5

СОЦИАЛЬНАЯ ПСИХОЛОГИЯ

понимание коммуникации и критическое суждение. Мы обозначили его как «сопереживание». Он входит в фактор «практические навыки» в теоретической модели М. Барретта, но в рамках эмпирических исследований в группе российских девушек студенток-международников получил самостоятельное развитие.

Четвертый фактор обозначили как «гражданское сознание». Он действует как независимый фактор при анализе эмпирических данных на российской выборке девушек студенток-международников и является важным в группе респонденток, отражая их стремление к более полной гражданской идентичности.

\begin{tabular}{|c|c|c|}
\hline \multirow[b]{2}{*}{ Фактор } & \multirow[b]{2}{*}{ Переменные (утвержление опросника) } & Значение \\
\hline & & $\frac{\text { оракторной }}{\text { нагрузки }}$ \\
\hline \multirow{5}{*}{1} & 10. Способность к самообразованию & 0,743048 \\
\hline & 11. Способность к аналитическому и критическому мышлению & 0,879278 \\
\hline & 12. Умение слушать и наблюдательность & 0,727269 \\
\hline & 14. Гибкость и аАаптивность & 0,806847 \\
\hline & $\begin{array}{l}\text { 15. Коммуникабельность, мингвистические способности, навыки } \\
\text { общения на разных языках }\end{array}$ & 0,724481 \\
\hline \multirow{3}{*}{2} & 2. Уважение культурного многообразия & 0,820015 \\
\hline & $\begin{array}{l}\text { 4. Открытость по отношению к иным культурам, верованиям, } \\
\text { мировоззрениям и обычаям }\end{array}$ & 0,804075 \\
\hline & 5. Уважение & 0,787560 \\
\hline \multirow{2}{*}{3} & 13. Сопереживание & 0,782121 \\
\hline & 19. Знание и критическое осмысление языковых стилей в общении & 0,725262 \\
\hline 4 & 6. ГражАанское самосознание & 0,766050 \\
\hline
\end{tabular}

Полученные данные позволяют представить модель соотнесения содержательного наполнения факторов в теоретической модели М. Барретта и на основе эмпирических данных в группе девушек студенток-международников (рис. 1). 
МахмУтова Е. Н., ЧУГАНСКАЯ А. А., ВОевОДА Е. В.

СПЕЦИФИКА ФАКТОРНОЙ СТРУКТУРЫ МЕЖКУЛЬТУРНОЙ КОМПЕТЕНТНОСТИ СТУДЕНТОВ...

Российский психологический жУРнАл, 2020, Т. 17, № 3, 60-75. doi: 10.21702/rpj.2020.3.5

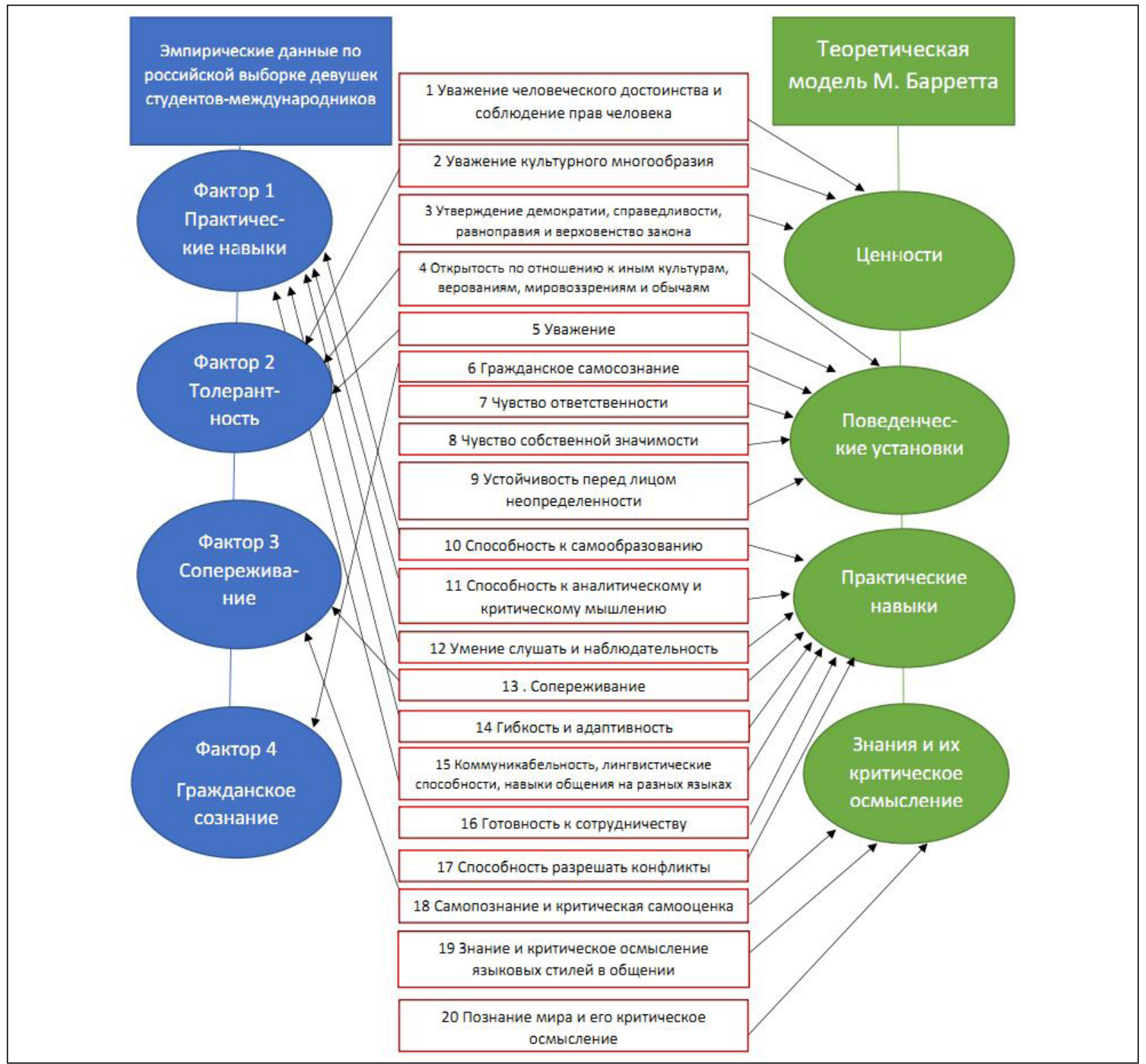

Рисунок 1. Соотнесение солержания переменных в теоретической молели и эмпирических Аанных на выборке российских Аевушек стуленток-межАународников

Таким образом, факторизация данных в группе российских девушек студенток-международников позволяет говорить о подтверждении гипотезы 1 исследования о существовании различий между факторными структурами в теоретической модели М. Барретта и эмпирическими данными ввиду наличия различного их компонентного наполнения при одинаковом количестве (4 фактора).

Следующим этапом исследования стала факторизация оценочных баллов в группе юношей студентов-международников. Были выделены 4 фактора с общим процентом объясняемой дисперсии $71 \%$ : 
МахмУтова Е. Н., ЧУГАНСКАЯ А. А., ВОЕвоДА Е. В.

СПЕЦИФИКА ФАКТОРНОЙ СТРУКТУРЫ МЕЖКУЛЬТУРНОЙ КОМПЕТЕНТНОСТИ СТУДЕНТОВ..

РосСИЙСКИй пСИХологИЧЕСКИй ЖУРнАл, 2020, Т. 17, № 3, 60-75. doi: 10.21702/rpj.2020.3.5

фактор 1 - «ответственность и уважение» (42\% общей объясняемой дисперсии); фактор 2 - «адаптивность» (11\% общей объясняемой дисперсии); фактор 3 - «сопереживание» (9\% общей объясняемой дисперсии); фактор 4 - «толерантность» (7\% общей объясняемой дисперсии).

Компонентный состав каждого из факторов, также как и в группе девушек, отличался от теоретической модели М. Барретта и включал от одного до восьми переменных (утверждений опросника) со значимым показателем факторной нагрузки (табл. 2).

\begin{tabular}{|c|c|c|}
\hline \multicolumn{3}{|c|}{$\begin{array}{l}\text { Таблица } 2 \\
\text { Факторные нагрузки переменных по } 4 \text { фракто } \\
\text { по оценке межкультурной компетентности }\end{array}$} \\
\hline ФakTOP & Переменные (утвержление опросника) & $\frac{\frac{\text { Значение }}{\text { dракторной }}}{\underline{\text { нагрузки }}}$ \\
\hline \multirow{8}{*}{1} & $\begin{array}{l}\text { 1. Уважение человеческого достоинства и соблюдение прав } \\
\text { человека }\end{array}$ & 0,715361 \\
\hline & 2. Уважение культурного многообразия & 0,748787 \\
\hline & 5. Уважение & 0,751309 \\
\hline & 6. ГражАанское самосознание & 0,829318 \\
\hline & 7. Чувство ответственности & 0,935726 \\
\hline & 10. Способность к самообразованию & 0,796722 \\
\hline & 11. Способность к аналитическому и критическому мышлению & 0,746110 \\
\hline & 17. Способность разрешать конфрликты & 0,739508 \\
\hline 2 & 14. Гибкость и аАаптивность & 0,742992 \\
\hline 3 & 13. Сопереживание & 0,876721 \\
\hline 4 & $\begin{array}{l}\text { 4. Открытость по отношению к иным культурам, верованиям, } \\
\text { мировоззрениям и обычаям }\end{array}$ & 0,946386 \\
\hline
\end{tabular}

Наиболее информативные данные были получены по первому фактору. Он отражает уважение, ответственность, человеческое достоинство, самопознание, критическое мышление, способность урегулировать конфликты и был обозначен нами как «ответственность и уважение».

Второй фактор включал утверждения, отражающие гибкость, адаптируемость, знание мира, критическое суждение. Этот фактор можно обозначить как «адаптивность».

Третий фактор может быть обозначен как «эмпатия». Этот фактор формируется как самостоятельный и в группе юношей-студентов, и в группе девушек.

Четвертый фактор был обозначен как «толерантность».

Соотнесение компонентов факторов в теоретической модели и эмпирических данных для группы юношей студентов-международников показывает различия в содержании переменных (рис. 2). 
МахмУтОва Е. Н., ЧУГАНСКАЯ А. А., ВОевОДА Е. В.

СПЕЦИФИКА ФАКТОРНОЙ СТРУКТУРЫ МЕЖКУЛЬТУРНОЙ КОМПЕТЕНТНОСТИ СТУДЕНТОВ...

РосСиЙский психологичЕский жУРнАл, 2020, Т. 17, № 3, 60-75. doi: 10.21702/rpj.2020.3.5

СОЦИАЛЬНАЯ ПСИХОЛОГИЯ

В группе юношей были выделены четыре фактора на основе факторизации эмпирических данных, которые в смысловом плане не совпадают с компонентами теоретической модели межкультурной компетентности (ценности, установки, практические навыки, знания и их критическое осмысление). Это позволяет говорить о подтверждении гипотезы 1 о наличии различий в факторной структуре теоретической модели М. Барретта и эмпирических данных в группе юношей студентов-международников.

Анализ данных оценки утверждения межкультурной компетентности по опроснику М. Барретта позволяет выявить следующие факторы в группе юношей студентов-международников: уважение и ответственность, адаптивность, сопереживание, толерантность. При этом в группе девушек была определена иная структура факторов: практические навыки, толерантность, сопереживание, гражданское сознание. При общем совпадении количества факторов отмечаются различия в их содержании. В обеих группах присутствуют общие факторы «толерантность» и «сопереживание», а также присутствуют по 2 различных фактора. Полученные данные позволяют говорить о частичном подтверждении гипотезы 2 о наличии различий в факторной структуре межкультурной компетентности в группе девушек и юношей по двум факторам из четырех.

\section{Обсуждение результатов}

Сопоставление полученных эмпирических данных с теоретической моделью М. Барретта показало, что в группе российских юношей и девушек в возрасте от 17 до 23 лет, обучающихся в университете международного профиля, представлены основные компоненты межкультурной компетентности.

При сопоставлении структур факторов в группах юношей и девушек можно отметить независимый приоритетный выбор ими утверждений, составивших содержание факторов «сопереживание» и «толерантность». На наш взгляд, этот результат экспериментально подтверждает «тенденцию гендерной деполяризации», о которой было упомянуто в теоретической части (Айвазова, 2017; Клецина и Иоффе, 2017), и показывает общее ценностно-смысловое основание межкультурного взаимодействия у исследованных студентов. Однако степень выраженности этого ценностно-смыслового основания у девушек и юношей различна. При одинаковой с юношами способности к сопереживанию девушки оказались более компетентными в знании и критическом осмыслении языковых стилей в общении (утверждение 19).

Этот вывод подтверждает важность знаний иностранных языков и культурной осведомленности как компонентов межкультурной компетентности, отмеченных другими авторами (Shevchenko, Bugrova, Cherniavskaya, \& Kostikova, 2018), и уточняет гендерную специфичность проявления этого качества. Исследования роли сопереживания в межкультурной коммуникации проводились и ранее (Chen, 2013; Fedotova, Makhmutova, Kostikova, \& Gugutsidze, 2018), однако в данном исследовании сопереживание как психологическое явление рассматривается в качестве одного из ведущих структурных компонентов межкультурной компетентности.

В проявлениях толерантности у юношей и девушек общей оказалась открытость к иным культурам, верованиям, мировоззрениям и обычаям (утверждение 4), но у девушек этот фактор еще усилен уважением к культурному многообразию (утверждение 2) и уважением как общей поведенческой установкой (утверждение 5). Полученный результат согласуется с позицией других авторов, отмечающих толерантность, наряду с доверием и сенситивностью, в качестве компонента межкультурной коммуникативной компетентности (Почебут, 2013). 
МаХМУТОва Е. Н., ЧУГАНСКАЯ А. А., ВОевОДА Е. В.

СПЕЦИФИКА ФАКТОРНОЙ СТРУКТУРЫ МЕЖКУЛЬТУРНОЙ КОМПЕТЕНТНОСТИ СТУДЕНТОВ..

РосСИЙСКИй пСИХологИЧЕСКИй ЖУРнАл, 2020, Т. 17, № 3, 60-75. doi: 10.21702/rpj.2020.3.5

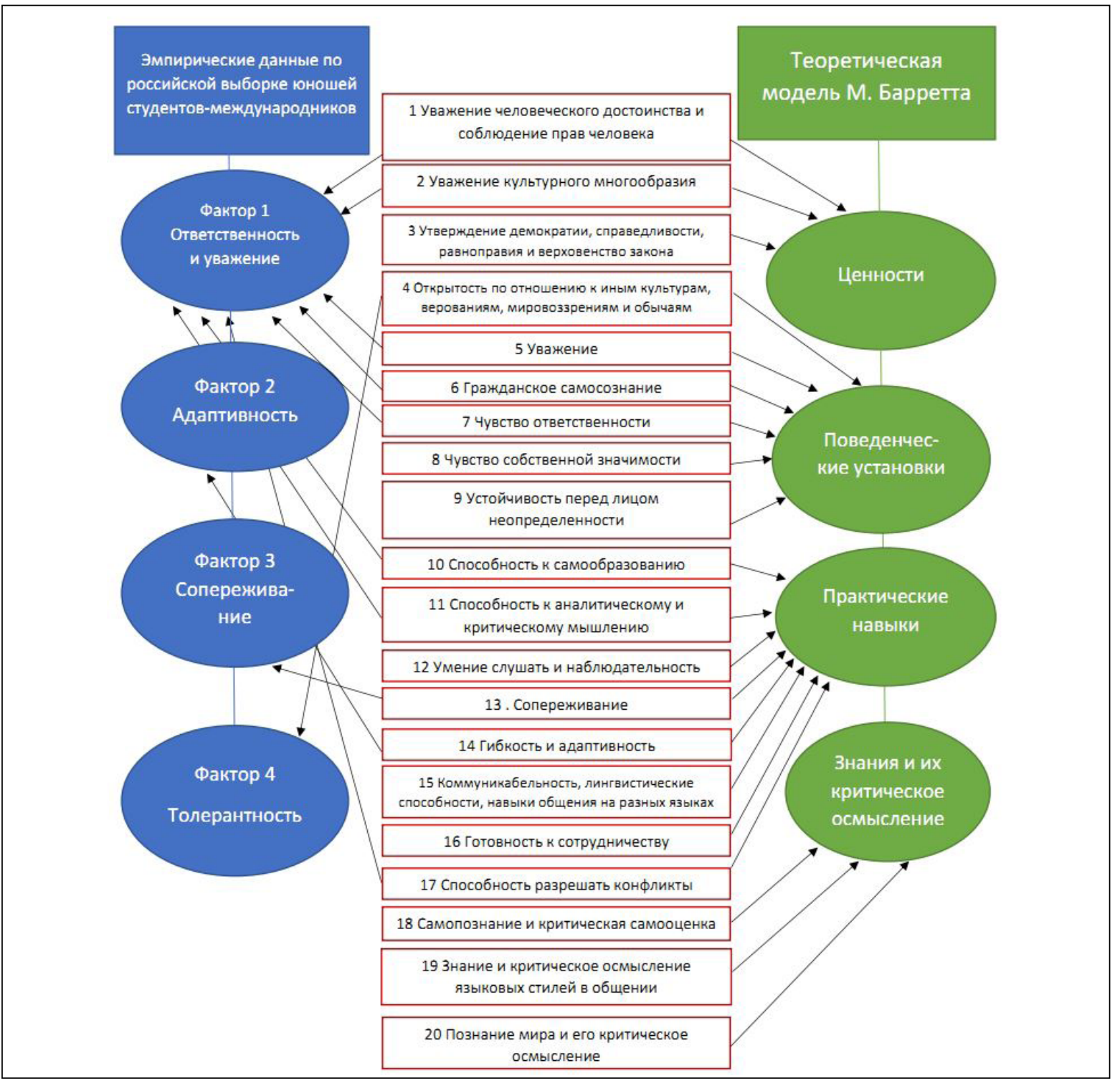

Рисунок 2. Соотнесение солержания переменных в теоретической модели и эмпирических Аанных на выборке российских юношей студентов-межАународников

Эмоциональные, когнитивные и поведенческие проявления гибкости и адаптивности учащихся как компонентов межкультурной компетентности были отчасти проанализированы нами ранее (Makhmutova, Kovtun, Kostikova, \& Revkova, 2018), а в данном исследовании получили уточнение в гендерном аспекте. Обнаруженные различия по факторам «практические навыки» и «гражданское сознание» в группе девушек, а также "уважение и ответственность» и «адаптивность» в группе юношей могут свидетельствовать о гендерно специфичных основаниях межкультурного взаимодействия и, соответственно, различных механизмах формирования межкультурной компетентности у девушек и юношей. 
МахмУтОва Е. Н., ЧУГАНСКАЯ А. А., ВОевОДА Е. В.

СПЕЦИФИКА ФАКТОРНОЙ СТРУКТУРЫ МЕЖКУЛЬТУРНОЙ КОМПЕТЕНТНОСТИ СТУДЕНТОВ...

РосСиЙский психологичЕский жУРнАл, 2020, Т. 17, № 3, 60-75. doi: 10.21702/rpj.2020.3.5

СОЦИАЛЬНАЯ ПСИХОЛОГИЯ

Проведенное исследование подтвердило, что формирование моделей конструктивного взаимодействия представителей различных культур нуждается в педагогическом и методическом обеспечении. В поликультурном обществе наиболее актуальной становится разработка учебных программ, в которых студенты учатся использовать свои психические качества в постоянно меняющихся ситуациях межкультурного взаимодействия.

Приобретение межкультурных компетенций важно не только для личного, но и для профессионального развития, особенно в профессиях, связанных с гуманитарными, политическими, экономическими международными отношениями. Это является значимым компонентом профессиональной картины мира будущих специалистов-международников. Наше исследование показало, что юноши и девушки 17-23 лет, обучающиеся в высшем учебном заведении по специальности, связанной с межкультурным взаимодействием, проявляют семантическое и инструментальное разнообразие в отношении ценностей, поведенческих установок, практических навыков и знаний. Другими словами, российские девушки и юноши, соотнося со своими поведенческими и мировоззренческими приоритетами утверждения опросника М. Барретта, формируют гендерно чувствительную межкультурную компетентность как основу реализации будущей профессиональной деятельности в сфере международных отношений.

Несмотря на конструктивный посыл Совета Европы выработать и внедрить общие механизмы формирования межкультурной компетентности как части культуры демократии, надо признать наличие ценностно-смысловой специфичности этих механизмов. Полученные нами результаты можно считать перспективными для дальнейших исследований межкультурной компетентности: с одной стороны, в направлении теоретического обоснования существования системообразующих компетенций в структуре межкультурной компетентности; с другой стороны, в практической диагностике своеобразия межкультурной компетентности, которая может выступить либо препятствием, либо катализатором межкультурного взаимодействия в будущей профессиональной деятельности студентов-международников.

Полученные результаты и выводы позволяют обратить внимание на важность гендерной специфики в ходе совершенствования педагогических приемов по развитию межкультурной компетентности студентов - будущих специалистов по международным отношениям.

\section{Благодарности}

Мы благодарим студентов, принявших участие в исследовании.

Работа выполнена при частичной поддержке РФФИ (проект № 19-29-07163-МК).

\section{Литература}

Агеев, В. С. (1990). Межгрупповое взаимодействие: социально-психологические проблемы. Москва: Изд-во Моск. ун-та.

Айвазова, С. Г. (2017). Гендерный дискурс в поле консервативной политики. Женщина в российском обществе, 4, 3-13. doi: 10.21064/WinRS.2017.4.1

Большакова, О. Б. (2019). Формирование межкультурной коммуникативной компетентности у студентов вуза в контексте ресурсного подхода (кандидатская диссертация). Хабаровск.

Воевода, Е. В. (2016). Межкультурная коммуникация в межэтническом образовательном пространстве. Научные исследования и разработки: Современная коммуникативистика, 3 (22), 24-28.

Гонина, О. О. (2017). Толерантность педагогов на различных этапах их профессионализации. Бизнес и дизайн ревю, 7(3), 13. 
МахмУтова Е. Н., ЧУГАНСКАЯ А. А., ВОЕвоДА Е. В.

СПЕЦИФИКА ФАКТОРНОЙ СТРУКТУРЫ МЕЖКУЛЬТУРНОЙ КОМПЕТЕНТНОСТИ СТУДЕНТОВ..

РосСИЙСКИЙ пСИХОЛОГИЧЕСКИЙ ЖУРнАл, 2020, Т. 17, № 3, 60-75. doi: 10.21702/rpj.2020.3.5

СОЦИАЛЬНАЯ ПСИХОЛОГИЯ

Гридунова, М.В. (2018). Психологические факторы межкультурной компетентности студентов и школьников (кандидатская диссертация). РУДН, Москва.

Клецина, И. С. и Иоффе, Е. В. (2017). Гендерные нормы как социально-психологический феномен. Москва: Проспект.

Корнилова, М.В.(2012). Динамика межкультурной компетентности в моно- и поликультурных группах: на материале межкультурного тренинга (кандидатская диссертация). МГППУ, Москва.

Корнилова, Т. В. и Чумакова, М. А. (2014). Шкалы толерантности и интолерантности к неопределенности в модификации опросника С. Баднера. Экспериментальная психология, 7(1), 92-110.

Костикова, Л. П. (2018). Поликультурные аспекты профессиональной подготовки будущего педагога. Педагогика, 3, 74-79.

Лебедева, Н. М., Лунева, О. В., Стефаненко, Т. Г. и Мартынова, М. Ю. (2003). Межкультурный диалог: тренинг этнокультурной компетентности. Москва: Изд-во РУДН.

Лебедева, Н. М., Татарко, А. Н. и Берри, Дж. (2016). Социально-психологические основы мультикультурализма: проверка гипотез о межкультурном взаимодействии в российском контексте. Психологический журнал, 37(2), 92-104.

Логашенко, Ю. А. (2015). Межкультурная сенситивность студентов в полиэтничной среде (кандидатская диссертация). СПбГУ, Санкт-Петербург.

Писаренко, А.Н.(2011). Формирование профессиональной межкультурной компетентности студентов (кандидатская диссертация). Саратовский государственный университет имени Н. Г. Чернышевского, Саратов.

Почебут, Л. Г. (2007). Теория межкультурной коммуникативной компетентности. Вестник СанктПетербургского университета. Серия 6. Философия, политология, социология, психология, право, международные отношения, 3, 23-33.

Почебут, Л. Г. (2013). Межкультурная коммуникативная компетентность как выражение человеческих отношений. Психологический журнал, 34(4), 5-15.

Почебут, Л. Г. (2017). Межкультурная коммуникативная компетентность: толерантность или ассертивность. Вестник Удмуртского университета. Серия Философия. Психология. Педагогика, 27(2), 189-195.

Радина, Н. К. (2012). Гендерная методология в социальной психологии. Социальная психология и общество, 3(3), 36-47.

Садохин, А. П. (2009). Межкультурная компетентность: сущность и механизмы формирования (докторская диссертация). РАГС, Москва.

Совет Европы (2016). Знания, умения и навыки, лежащие в основе культуры демократии. Основные положения. Доступ 19 декабря 2019, источник https://rm.coe.int/coermpubliccommonsearchservices/ displaydctmcontent?documentid $=09000016806 \mathrm{ccf16}$

Солдатова, Г. У. и Пантелеев, А. Б. (2007). Межкультурная компетентность и адаптация в инокультурной среде: подходы и технологии. Вестник Московского государственного областного университета. Серия: Педагогика, 1, 12-22.

Солдатова, Г. У. и Шайгерова, Л. А. (2015). Теории и модели межкультурной коммуникации в западной психологии. В Понять другого: Межкультурное взаимопонимание в современном глобальном мире (с. 104-106). Москва: Изд-во Московского государственного психолого-педагогического университета.

Стефаненко, Т. Г. (2009). Этническая идентичность: от этнологии к социальной психологии. Вестник Московского университета. Серия 14: Психология, 2, 3-17. 
МахмУтова Е. Н., ЧУГАНСКАЯ А. А., ВоеводА Е. В.

СПЕЦИФИКА ФАКТОРНОЙ СТРУКТУРЫ МЕЖКУЛЬТУРНОЙ КОМПЕТЕНТНОСТИ СТУДЕНТОВ...

РосСиЙский психологичЕский жУРнАл, 2020, Т. 17, № 3, 60-75. doi: 10.21702/rpj.2020.3.5

СОЦИАЛЬНАЯ ПСИХОЛОГИЯ

Хухлаев, О. Е. и Чибисова, М. Ю. (2010). Теоретические и практические вопросы межкультурной коммуникации: современные тенденции. Психологическая наука и образование, 5, 168-179.

Хухлаев, О. Е., Гриценко, В. В., Павлова, О. С., Ткаченко, Н. В., Усубян, Ш. А. и Шорохова, В. А. (2020). Принципы построения авторской комплексной модели межкультурной компетентности. В В. В. Константинов (отв. ред.), Социально-психологическая адаптация мигрантов в современном мире. Материалы 5-й Международной научно-практической конференции (с. 238-245). Москва: Перо.

Чуганская, А. А. (2018). Этнокультурные ценности как предикторы профессиональной компетентности государственных служащих в современном обществе. В И. Л. Сурат (отв. ред.), Актуальные проблемы развития экономики в современных условиях: Материалы международной научно-практической конференции (с. 557-559). Москва: Изд-во Современного гуманитарного университета.

Янкина, Н. В. (2006). Формирование межкультурной компетентности студента университеma (докторская диссертация). Оренбургский государственный университет, Оренбург.

Barrett, M. (2018). How schools can promote the intercultural competence of young people. European Psychologist, 23(1), 93-104. doi: 10.1027/1016-9040/a000308

Barrett, M., Byram, M., Lázár, I., Mompoint-Gaillard, P., \& Philippou, S. (2014). Developing intercultural competence through education (Pestalozzi series No. 3). Strasbourg: Council of Europe Publishing. Retrieved from https://rm.coe.int/developing-intercultural-enfr/16808ce258

Bartel-Radic, A., \& Giannelloni, J.-L. (2017). A renewed perspective on the measurement of cross-cultural competence: An approach through personality traits and cross-cultural knowledge. European Management Journal, 35(5), 632-644. doi: 10.1016/j.emj.2017.02.003

Berry, J. W. (1997). Immigration, acculturation, and adaptation. Applied Psychology, 46(1), 5-34. doi: 10.1111/j.1464-0597.1997.tb01087.x

Borghetti, C. (2017). Is there really a need for assessing intercultural competence? Some ethical issues. Journal of Intercultural Communication, 44. Retrieved from https://immi.se/intercultural/nr44/borghetti.html

Bowen, T. (2020). Examining students' perspectives on gender bias in their work-integrated learning placements. Higher Education Research \& Development, 39(3). doi: 10.1080/07294360.2019.1677568

Byram, M. (2008). From foreign language education to education for intercultural citizenship: Essays and Reflections. Multilingual Matters.

Byram, M., Golubeva, I., Hui, H., \& Wagner, M. (Eds). (2016). From principles to practice in education for intercultural citizenship. Bristol: Multilingual Matters.

Chen, Ch. (2013). Empathy in language learning and its inspiration to the development of intercultural communicative competence. Theory and Practice in Language Studies, 3(12), 2267-2273. doi: 10.4304/tpls.3.12.2267-2273

Council of Europe (2016). Competences for democratic culture. Living together as equals in culturally diverse democratic societies. Strasbourg: Council of Europe Publishing. Retrieved from https://rm.coe. int/16806ccc07

Deardorff, D. K. (2011). Assessing intercultural competence. New Directions for Institutional Research, 2011(149), 65-79. doi: 10.1002/ir.381

Fedotova, O. S., Makhmutova, E. N., Kostikova, L. P., \& Gugutsidze, E. Z. (2018). Empathy as a part of professional culture of the specialist. The European Proceedings of Social \& Behavioural Sciences, 32-40. doi: 10.15405/epsbs.2018.12.02.4 
МахмУтова Е. Н., ЧУГАНСКАЯ А. А., ВОЕвоДА Е. В.

СПЕЦИФИКА ФАКТОРНОЙ СТРУКТУРЫ МЕЖКУЛЬТУРНОЙ КОМПЕТЕНТНОСТИ СТУДЕНТОВ...

РосСИЙСКИЙ пСИХОЛОГИЧЕСКИЙ ЖУРнАл, 2020, Т. 17, № 3, 60-75. doi: 10.21702/rpj.2020.3.5

СОЦИАЛЬНАЯ ПСИХОЛОГИЯ

Griffith, R. L., Wolfeld, L., Armon, B. K., Rios, J., \& Liu, O. L. (2016). Assessing intercultural competence in higher education: Existing research and future directions. ETS Research Report Series, 2016(2), 1-44. doi: 10.1002/ets2.12112

Ilyushina, A., Prishvina, V., Shevchenko, B., Kostikova, L., \& Belogurov, A. (2018). Cultural values of university students: Self-assessment and peer-assessment. Proceedings of 4th International Conference on Arts, Design and Contemporary Education, 579-583. doi: 10.2991/icadce-18.2018.122

Kostikova, L. P., Cherniavskaya, E. S., Balakhovskaya, Y. I., \& Zakharchenko, O. V. (2019). Analytical and critical thinking skills of cadets and post-graduate students. The European Proceedings of Social \& Behavioural Sciences, 145-152. doi: 10.15405/epsbs.2019.12.17

Kostikova, L. P., Prishvina, V. V., Ilyushina, A. V., Krutova, I. Yu., \& Fedotova, O. S. (2018). What does intercultural competence mean to university students? SGEM International Multidisciplinary Scientific Conference on Social Sciences and Arts, 5(3.4), 919-926. doi: 10.5593/sgemsocial2018/3.4

Kostikova, L., Prishvina, V., llyushina, A., Fedotova, O., \& Belogurov, A. (2018). Culture in teaching English as a foreign language. Proceedings of the 2nd International Conference on Culture, Education and Economic Development of Modern Society, 13-17. doi: 10.2991/iccese-18.2018.4

Lantz-Deaton, C. (2017). Internationalisation and the development of students' intercultural competence. Teaching in Higher Education, 22(5), 532-550. doi: 10.1080/13562517.2016.1273209

Liferov, A., \& Kostikova, L. (2017). Russian higher education meeting challenges of 21st century labour market. International Journal for 21st Century Education, 4(S), 51-58.

Mahmutova, E. (2019). Specifics of acquisition of cross-cultural competence by international relations students. In XVI European Congress of Psychology (p. 258). Moscow: Lomonosov Moscow State University Publ.

Makhmutova, E. N., Kovtun, N. V., Kostikova, L. P., \& Revkova, E. A. (2018). International students: Flexibility and adaptation issues. The European Proceedings of Social \& Behavioural Sciences, 198-204. doi: 10.15405/epsbs.2018.12.02.22

Oreshkin, N. B., Shlykov, Yu. N., Shevchenko, B. A., Kostikova, L. P., \& Belogurov, A. Yu. (2019). Tolerance of ambiguity of cadets in the military school. Proceedings of the 3rd International Conference on Culture, Education and Economic Development of Modern Society, 837-841. doi: 10.2991/iccese-19.2019.180

Porto, M., \& Byram, M. (2015). Developing intercultural citizenship education in the language classroom and beyond. Argentinian Journal of Applied Linguistics, 3(2), 9-29.

Shevchenko, B. A., Bugrova, E. I., Cherniavskaya, E. S., \& Kostikova, L. P. (2018). Professional culture of the military: Linguistic, communicative and plurilingual skills. The European Proceedings of Social \& Behavioural Sciences, 191-197. doi: 10.15405/epsbs.2018.12.02.21

Stefanenko, T. G., \& Kupavskaya, A. S. (2010). Ethno-cultural competence as a component of competence in communication. Psychology in Russia: State of the Art, 3, 550-564. doi: 10.11621/pir.2010.0027

Stepanov, E. V., Andreev, M. V., Gavzov, V. V., Novikov, S. V., \& Kostikova, L. P. (2019). Cooperation skills in professional activity of the military. Proceedings of the 3rd International Conference on Culture, Education and Economic Development of Modern Society, 487-491. doi: 10.2991/iccese-19.2019.109

Wagner, M., Perugini, D. C., \& Byram, M. (Eds). (2017). Teaching intercultural competence across the age range: From theory to practice. Multilingual Matters. doi: 10.21832/WAGNER8903

Конфликт интересов отсутствует 